\title{
Aditivos químicos ou biológicos na ensilagem de cana-de-açúcar. 2. Parâmetros ruminais e degradabilidade da matéria seca e das frações fibrosas
}

\author{
Patrick Schmidt ${ }^{1}$, Luiz Gustavo Nussio ${ }^{2}$, Maity Zopollatto ${ }^{3}$, José Leonardo Ribeiro ${ }^{3}$, Vanessa \\ Pillon dos Santos ${ }^{3}$, Alexandre Vaz Pires ${ }^{2}$
}

${ }^{1}$ UNESP - Campus Experimental de Registro - Doutor em Ciência Animal e Pastagens - USP/ESALQ - Av. Pádua Dias, 11 CEP: $13418-900$ - Piracicaba, SP

2 Departamento de Zootecnia - USP/ESALQ - Piracicaba, SP

3 Pós-graduação em Ciência Animal e Pastagens - USP/ESALQ - Piracicaba, SP.

RESUMO - Objetivou-se avaliar o efeito da inclusão de aditivos na ensilagem de cana-de-açúcar (Saccharum officinarum L.) sobre a degradação de MS e de componentes da parede celular e sobre os parâmetros de fermentação ruminal em bovinos alimentados com dietas contendo essas silagens. Utilizaram-se cinco novilhos da raça Nelore providos de cânula ruminal, alocados em delineamento quadrado latino $5 \times 5$ e alimentados com dietas com $65 \%$ de volumoso (\%) MS. Foram avaliadas cinco silagens (base úmida): controle - cana-de-açúcar, sem aditivos; uréia - cana-de-açúcar $+0,5 \%$ ureia; benzoato - cana-de-açúcar $+0,1 \%$ de benzoato de sódio; LP - cana-de-açúcar inoculada com Lactobacillus plantarum $\left(1 \times 10^{6} \mathrm{ufc} / \mathrm{g} \mathrm{MV}\right)$; LB - cana-de-açúcar inoculada com L. buchneri $\left(3,6 \times 10^{5} \mathrm{ufc} / \mathrm{g}\right.$ forragem). A forragem foi armazenada em silos do tipo poço por 90 dias antes do fornecimento aos animais. Os parâmetros ruminais foram afetados de forma moderada pelas silagens e tiveram forte efeito do horário de coleta de amostras. As concentrações molares médias dos ácidos acético, propiônico e butírico foram de 60,9;19,3 e 10,2 mM, respectivamente. O ambiente ruminal proporcionado por dietas formuladas com silagens de cana-de-açúcar foi satisfatório e similar ao tradicionalmente observado em dietas contendo cana. $O$ uso de aditivos na ensilagem influenciou, de forma não-significativa, a degradabilidade ruminal da MS e da MO, mas não alterou a degradabilidade ruminal da fração fibrosa. Os aditivos aplicados à cana-de-açúcar resultaram em pequenas alterações na maior parte das variáveis avaliadas. Apesar de a degradabilidade ruminal das silagens ter sido pouco afetada pelo uso de aditivos, os valores observados foram próximos aos observados para a cana-de-açúcar in natura.

Palavras-chave: aditivos, AGV, bovinos de corte, conservação de forragem, metabolismo, perdas

\section{Chemical and biological additives in sugar cane silages. 2. Ruminal parameters and DM and fiber degradabilities}

\footnotetext{
ABSTRACT - The objective was to evaluate the addition of additives in the ensiling of sugar cane (Saccharum officinarum L.) on the degradation of DM and components of cellular wall and on ruminal fermentation parameters in bovines fed with diets containing these silages. Five rumen-cannulated Nelore steers were allotted to a $5 \times 5$ latin square design. The steers were placed in metabolic cages and fed diets with $65 \%$ forage (\%DM). Five silages were evaluated (wet basis): Control - sugar cane, no additives; Urea - sugar cane $+0.5 \%$ of urea; Benzoate - sugar cane + $0.1 \%$ of sodium benzoate; LP - sugar cane inoculated with - Lactobacillus plantarum ( $1 \times 10^{6} \mathrm{cfu} / \mathrm{g}$ forage $)$; LB sugar cane inoculated with L. buchneri $\left(3.6 \times 10^{5} \mathrm{cfu} / \mathrm{g}\right.$ forage). During 90 days, before the animal feeding, the forage was stocked in vertical silos.Ruminal parameters were slightly affected by the silages and a strong effect of sampling time. Averages of molar concentration of acetic, propionic and butyric acids were 60.9, 19.3, and 10.2 mM, respectively. Ruminal environment proportionate by the formulated diets with sugar cane sugar silages was satisfactory and similar to traditionally observed in diets containing sugar cane. The additive used in the ensiling influenced, in a no-significant form, the ruminal degradability of DM an OM, but it did not alter the ruminal degradability of the fiber fraction. The additives applied to the sugar cane resulted in slightly alterations? for most evaluated variable. Although the ruminal degradability of silages was little affected by the additive use, the observed values were similar to the observed for the sugar cane in natura.
}

Key Words: additives, beef cattle, forage conservation, losses, metabolism, VFA 


\section{Introdução}

Em silagens de cana-de-açúcar, a fermentação alcoólica, mediada pela população de leveduras epífitas característica da cana-de-açúcar, pode representar perdas de MS superiores a $35 \%$, em decorrência da produção de duas moléculas de $\mathrm{CO}_{2}$ e duas de etanol (volátil) para cada molécula de glicose metabolizada (McDonald et al., 1991). O elevado metabolismo e a perda da fração de carboidratos solúveis $(\mathrm{CHO})$ provoca aumento centesimal relativo das demais frações da forragem, notadamente os componentes da parede celular. Dados apresentados por Siqueira (2005) revelaram aumento médio de $36,5 \%$ no teor de FDN das silagens em comparação à cana fresca.

Muitos trabalhos têm sido realizados para avaliação do uso de aditivos em silagens de cana-de-açúcar. Entretanto, a maioria destaca a composição químico-bromatológica das silagens, as perdas decorrentes do processo de conservação e desempenho de animais. Contudo, ainda são incipientes os dados sobre a degradação de nutrientes das silagens e os parâmetros fermentativos no rúmen de animais alimentados com esse volumoso.

A concentração ruminal de ácidos graxos voláteis (AGV) e o pH ruminal são bons indicativos dos padrões de fermentação das dietas fornecidas aos animais (Bergman, 1990) e podem servir para comparação entre fontes de alimentos alternativas e alimentos tradicionais. Do mesmo modo, a concentração de amônia ruminal é determinante do crescimento da população microbiana e influencia diretamente a digestão da fração fibrosa da ração consumida. Essa concentração é conseqüência do equilíbrio entre a produção, a absorção e a utilização pelos microrganismos ruminais (Van Soest, 1994).

Técnicas de determinação da degradabilidade in situ de alimentos têm sido usadas para obtenção de informações quantitativas sobre a taxa e extensão da degradação ruminal de nutrientes usadas no estabelecimento de modelos de predição de consumo e fermentação ruminal (Huntington \& Givens, 1995).

Apesar de a cana-de-açúcar apresentar elevada fração “a” (açúcares solúveis), o que promoveria rápido crescimento microbiano no rúmen, essa forrageira apresenta baixa taxa de degradação ruminal da fibra potencialmente degradável "b2", o que pode reduzir a ingestão de MS e a disponibilidade de energia, limitando o desempenho produtivo dos animais (Fernandes et al., 2001).

O modelo de avaliação da degradabilidade in situ do programa Fit Curve, descrito por Hovell (1995), permite estimar, com base em curvas de degradabilidade ruminal, as frações "a" (intercepto da extrapolação da curva de degra- dação no tempo zero, ou fração prontamente solúvel no rúmen); "b" (assíntota da curva exponencial, ou fração potencialmente degradável); e "c" (taxa fracional constante da curva exponencial ou taxa de degradação constante da fração "b"). Com base nesses parâmetros, o programa estima a degradabilidade potencial e efetiva do alimento incubado, adotando taxas de passagem variáveis.

Objetivou-se nesta pesquisa avaliar o efeito do uso de aditivos químicos e bacterianos na ensilagem de cana-deaçúcar sobre a degradabilidade ruminal de MS e de componentes da parede celular e sobre os parâmetros ruminais de fermentação em bovinos alimentados com dietas contendo essas silagens.

\section{Material e Métodos}

O experimento foi realizado no Setor de Ruminantes e as análises químico-bromatológicas, no Laboratório de Bromatologia, ambos do Departamento de Zootecnia da USP/ESALQ, em Piracicaba, SP.

Foram confeccionadas cinco silagens: controle = canade-açúcar sem aditivo; uréia = cana-de-açúcar acrescida de $0,5 \%$ de uréia na massa verde $(\mathrm{MV})$; benzoato = cana-de-açúcar aditivada de $0,1 \%$ de benzoato de sódio na $\mathrm{MV} ; \mathrm{LP}=$ canade-açúcar inoculada com Lactobacillus plantarum, na dose de $1 \times 10^{6} \mathrm{ufc} / \mathrm{g}$ de MV; e LB = cana-de-açúcar inoculada com L. buchneri, na dose de 3,6 $\times 10^{5} \mathrm{ufc} / \mathrm{g}$ de $\mathrm{MV}$.

Utilizaram-se cinco bovinos machos castrados da raça Nelore, com peso inicial de $527 \pm 53 \mathrm{~kg}$, portadores de cânula ruminal, alojados em gaiolas para estudos de metabolismo, do tipo tie-stall, com 1,05 m de largura e 2,10 m de comprimento, providas de bebedouro, comedouro, piso emborrachado e canaleta com caixa coletora de fezes, em um delineamento quadrado latino $5 \times 5$ (cinco tratamentos, cinco animais e cinco períodos). Como suplementação vitamínica, os animais receberam por via parenteral subcutânea a aplicação de complexo vitamínico ADE no início do primeiro e do quarto período.

As dietas experimentais (Tabela 1) foram formuladas com base na composição em MS, usando-se as exigências de mantença dos animais, segundo o NRC Gado de Corte (1996), e continham 65\% de NDT e 12,5\% de PB. Os animais foram alimentados com as dietas experimentais em mistura total duas vezes ao dia ( 8 e $18 \mathrm{~h}$ ), em quantidade suficiente para permitir 10\% de sobras. A quantidade de ração fornecida e das sobras foi quantificada durante o período de avaliação para posterior cálculo de consumo. O concentrado utilizado em todas as dietas foi o mesmo, com exceção da silagem com $0,5 \%$ de uréia, cujo nível inclusão de uréia foi menor, em virtude do $\mathrm{N}$ residual dessa silagem. 
Tabela 1 - Composição das rações experimentais (\%MS) Table 1 - Composition of the experimental diets (\%DM)

\begin{tabular}{|c|c|c|c|c|c|}
\hline \multirow[t]{2}{*}{$\begin{array}{l}\text { Aditivo }{ }^{1} \\
\text { Additive }\end{array}$} & \multicolumn{5}{|c|}{$\begin{array}{c}\text { Ingrediente } \\
\text { Ingredient }\end{array}$} \\
\hline & $\begin{array}{l}\text { Silagem } \\
\text { Silage }\end{array}$ & $\begin{array}{c}\text { Milheto } \\
\text { Pearl } \\
\text { millet }\end{array}$ & $\begin{array}{c}\text { Farelo } \\
\text { de soja } \\
\text { Soybean } \\
\text { meal }\end{array}$ & $\begin{array}{l}\text { Uréia } \\
\text { Urea }\end{array}$ & Mineral \\
\hline $\begin{array}{l}\text { Controle } \\
\text { Control }\end{array}$ & 65,10 & 23,96 & 7,81 & 1,04 & 2,08 \\
\hline $\begin{array}{l}\text { Uréia } \\
\text { Urea }\end{array}$ & 65,38 & 24,58 & 7,85 & 0,10 & 2,09 \\
\hline $\begin{array}{l}\text { Benzoato } \\
\text { Benzoate }\end{array}$ & 65,10 & 23,96 & 7,81 & 1,04 & 2,08 \\
\hline LP & 65,10 & 23,96 & 7,81 & 1,04 & 2,08 \\
\hline LB & 65,10 & 23,96 & 7,81 & 1,04 & 2,08 \\
\hline
\end{tabular}

${ }^{1}$ Controle = cana-de-açúcar sem aditivo; uréia = cana + uréia; benzoato cana + benzoato de sódio; LP = cana + bactéria acidolática; LB = cana + bactéria heterolática (control = sugar cane without additive; urea = sugar cane + urea benzoate = sugar cane + sodium benzoate; $L P=$ sugar cane + acid lactic bacteria; $L B=$ sugar cane + heterolactic bacteria).

A degradação ruminal de MS, MO, FDN e FDA das silagens foi avaliada utilizando-se sacos de náilon com porosidade de 50 micrón, com $6,5 \times 13,0 \mathrm{~cm}$ de área útil (Nocek, 1988), inseridos no rúmen em duplicata, para cada silagem e horário de incubação, segundo metodologia descrita por Huntington \& Givens (1995). Durante cada período de adaptação, foram coletadas amostras de cada silagem para incubação. As silagens foram secas em estufa de ventilação forçada a $55^{\circ} \mathrm{C}$, por 72 horas e trituradas em moinho do tipo Wiley com peneira de malha de $2 \mathrm{~mm}$. Da forragem moída foi tirada uma nova alíquota para determinação da $\mathrm{MS}$ a $105^{\circ} \mathrm{C}$, por 8 horas. Os sacos de náilon foram pesados vazios e cheios com $6 \mathrm{~g}$ de MS (corrigida a $105^{\circ} \mathrm{C}$ ) de silagem, resultando em porções de $35 \mathrm{mg} \mathrm{de} \mathrm{MS} / \mathrm{cm}^{2}$ de tecido. Depois de devidamente lacrados, os sacos foram presos por uma argola a um mosquetão, o qual foi preso a uma corrente imersa no conteúdo ruminal e ancorada à cânula.

Foram adotados sete tempos de incubação: 0, 6, 12, 24, 48, 72 e 96 horas. A incubação foi realizada em ordem cronológica inversa, com a finalidade de retirar todos os sacos ao mesmo tempo, com exceção dos sacos do tempo zero, que não foram incubados, mas foram lavados juntamente aos demais.

No momento da retirada, os sacos foram lavados em água corrente por aproximadamente 2 horas até que a água não apresentasse sinais de resíduos de fluido ruminal. $\mathrm{O}$ excesso de água nos sacos foi retirado por leve pressão manual. Os sacos foram mantidos em estufa de ventilação forçada a $60^{\circ} \mathrm{C}$ por 72 horas até secagem completa e, posteriormente, foram pesados e o resíduo quantificado para posterior cálculo da taxa de desaparecimento. Os resíduos das duplicatas de cada tempo de incubação, para cada silagem, e período foram agrupados formando uma amostra composta. As amostras foram trituradas em moinho tipo Wiley com peneira de malha de $1 \mathrm{~mm}$ e analisadas quanto aos teores de MS, cinzas (AOAC, 1990), FDN e FDA, obtidos pelo método seqüencial utilizando-se o aparelho ANKOM Fiber Analyzer (ANKOMTechnology Corp.), descrito por Holden (1999).

Após as determinações químico-bromatológicas das frações MS, MO, FDN e FDA por análise convencional, os dados das amostras incubadas in situ foram processadas utilizando-se o programa FitCurve6 para Windows ${ }^{\circledR} \mathrm{XP}$, desenvolvido pela Rowett Research Institute, Bucksburn, Aberdeen, Escócia (http://www.macaulay.ac.uk/IFRU/ software).

As degradabilidades potenciais (DP) in situ de MS, MO, FDN e FDA foram calculadas segundo a equação 1:

$$
D P=a+b\left(1-e^{-c t}\right)
$$

em que $D P=$ degradabilidade potencial estimada $(\%) ; a=$ interseção da curva no tempo zero, que pode ser interpretada como fração rapidamente solúvel ( $\%$ do original); $b=$ fração insolúvel em água, mas potencialmente degradável (\% do original); $c=$ taxa de degradação constante da fração " $b$ " por hora (\%/hora); $e=\log$ aritmo natural; $t=$ tempo de incubação (horas); $a+b=$ potencial de degradabilidade.

A degradabilidade efetiva (DE) foi calculada segundo Ørskov \& McDonald (1979), conforme a equação 2:

$D E=a+b\left(\frac{(b x c)}{(c+k p)}\right)$

em que $D E=$ degradabilidade efetiva $(\%) ; a=$ interseção da curva no tempo zero, que pode ser interpretada como fração rapidamente solúvel (\% do original); $b=$ fração insolúvel em água, mas potencialmente degradável (\% do original); $c=$ taxa de degradação da fração " $b$ ” por hora (\%/hora); $k p=$ taxa de passagem da fase sólida (\%/hora).

Uma vez que não foi mensurada a taxa de passagem da fase sólida neste experimento, os valores de degradabilidade efetiva foram estimados pelo programa FitCurve6 para as taxas de passagem sugeridas de 2,5 e $8 \%$ /hora.

A partir do segundo dia do período de avaliação, amostras do líquido ruminal (aproximadamente $100 \mathrm{~mL}$ ) foram obtidas em diferentes tempos. A primeira amostragem foi realizada imediatamente antes da oferta de alimento matinal ( $8 \mathrm{~h})$ e as amostras subseqüentes foram colhidas a cada 4 horas, durante 48 horas, intercalando os tempos após as primeiras 24 horas para permitir obtenção dos tempos estabelecidos de $0,2,4,6,8,10,12,14,16,18,20$ e 22 horas após o fornecimento da dieta do período da manhã. 
Para coleta do líquido ruminal, foram tomadas amostras da digesta em vários pontos do rúmen. A digesta foi filtrada sob pressão manual em três camadas de tecido de algodão, coletando-se o líquido em béquer de vidro identificado por silagem $\mathrm{O}$ líquido foi homogeneizado e seu $\mathrm{pH}$ foi imediatamente determinado em potenciômetro digital DIGIMED ${ }^{\circledR}$ DMPH2. Do líquido recolhido, para cada silagem, em cada tempo, foram tomadas duas alíquotas de $50 \mathrm{~mL}$, que foram mantidas congeladas a $-20^{\circ} \mathrm{C}$, sem acidificação, em recipientes plásticos identificados e com tampa, para posteriores análises de nitrogênio amoniacal $\left(\mathrm{N}-\mathrm{NH}_{3}\right)$ e ácidos graxos voláteis $(\mathrm{AGV})$.

Após o descongelamento das amostras de fluido ruminal, $12 \mathrm{~mL}$ deste foram colocados em tubos e centrifugados a $12000 \mathrm{x} \mathrm{g}$, a $4^{\circ} \mathrm{C}$ durante 20 minutos. $\mathrm{Na}$ fração sobrenadante, determinou-se o teor de $\mathrm{N}-\mathrm{NH}_{3}$, pelo método colorimétrico proposto por Chaney \& Marbach (1962), efetuando-se as leituras em espectrofotômetro JENWAY-6405 UV/VIS ${ }^{\circledR}$, a $550 \mathrm{~nm}$.

A determinação dos AGV (ácidos acético, propiônico, butírico, isobutírico, valérico e isovalérico) foi realizada no fluido do outro recipiente, igualmente descongelado e centrifugado. Parte $(800 \mu \mathrm{L})$ do sobrenadante foi armazenada em frasco para leitura juntamente com $200 \mu \mathrm{L}$ de ácido metafosfórico e $100 \mu \mathrm{L}$ de padrão interno. As leituras foram realizadas em cromatógrafo líquido-gasoso, CLG, considerando como pool de AGV a soma das concentrações dos ácidos acético, propiônico, butírico, isobutírico, valérico e isovalérico.

A análise estatística dos dados foi realizada em delineamento experimental em quadrado latino $5 \times 5$, com efeitos balanceados de animais e períodos. Os dados foram analisados utilizando-se o programa estatístico $\mathrm{SAS}^{\circledR}$, versão 6.12 para Windows ${ }^{\circledR}$ (SAS, 1996). As médias da degradação ruminal foram comparadas pelo teste Tukey-Kramer, mediante procedimento PROC MIXED do SAS, considerando que os efeitos de período e animais são aleatórios, o que constitui um modelo misto. Do mesmo modo, as médias de pH, amônia e AGV foram comparadas pelo PROC MIXED, como avaliações repetidas no tempo.

\section{Resultados e Discussão}

Não houve interação tratamento $\times$ horário de coleta para nenhum dos parâmetros ruminais avaliados, portanto, as silagens promoveram efeito semelhante durante todo o período de amostragem.

A concentração de ácidos graxos voláteis (AGV) no fluido ruminal dos animais foi alterada pelas dietas fornecidas (Figura 1), com exceção dos ácidos isobutírico (IC4) e valérico (C5), que não diferiram entre as dietas e apresentaram concentrações molares médias de 1,00 e 1,03 mM.

A relação ácido acético:ácido propiônico apresentou valor médio de 3,21. O maior valor para esta relação foi obtido nos animais alimentados com a silagem LP $(3,56)$ e os menores, nos animais alimentados com as silagens com uréia e benzoato $(2,96$ e 3,02). Os valores obtidos para a relação ácidos acético:propiônico foram similares aos descritos por Silveira et al. (2002), que avaliaram o perfil ruminal de ácidos graxos voláteis ( $\mathrm{AGV}$ ) de bovinos alimentados com dietas contendo silagem de cana-de-açúcar aditivada com polpa cítrica e uréia e verificaram concentrações mola-

Tabela 2 - Ácidos graxos voláteis (AGV), pH e nitrogênio amoniacal no fluido ruminal de bovinos alimentados com rações contendo silagem de cana-de-açúcar

Table 2 - Volatile fatty acid (VFA), $\quad \mathrm{pH}$ and ammonia of ruminal in the ruminal fluid of beef cattle fed sugar cane silage based diets

\begin{tabular}{|c|c|c|c|c|c|c|c|c|c|c|}
\hline \multirow[t]{2}{*}{ Item } & \multicolumn{5}{|c|}{$\begin{array}{l}\text { Silagem } \\
\text { Silage }\end{array}$} & \multirow[t]{2}{*}{$\begin{array}{l}\text { Média } \\
\text { Mean }\end{array}$} & \multirow[t]{2}{*}{$\begin{array}{l}\mathrm{EP} \\
S E\end{array}$} & \multicolumn{3}{|c|}{$\begin{array}{c}\text { Efeito }^{1} \\
\text { Effect }\end{array}$} \\
\hline & $\begin{array}{c}\text { Controle } \\
\text { Control }\end{array}$ & $\begin{array}{l}\text { Uréia } \\
\text { Urea }\end{array}$ & $\begin{array}{c}\text { Benzoato } \\
\text { Benzoate }\end{array}$ & LP & LB & & & 1 & 2 & 3 \\
\hline \multicolumn{11}{|l|}{$\mathrm{AGV}, \mathrm{mM}(V F A, m M)$} \\
\hline Ácido acético (Acetic acid) & $63,10 \mathrm{ab}$ & $62,90 \mathrm{ab}$ & $57,80 \mathrm{ab}$ & $65,00 \mathrm{a}$ & $55,90 \mathrm{~b}$ & 60,90 & 3,33 & $*$ & $* *$ & ns \\
\hline Ácido isobutírico (Isobutyric acid) & 1,02 & 1,06 & 0,93 & 1,00 & 0,98 & 1,00 & 0,06 & ns & $* *$ & ns \\
\hline Ácido butírico (Butyric acid) & $10,50 b$ & $12,10 \mathrm{a}$ & $9,68 b$ & $9,69 b$ & $9,18 b$ & 10,20 & 0,42 & $* *$ & $* *$ & ns \\
\hline Ácido isovalérico (Isovaleric acid) & $1,98 \mathrm{a}$ & $1,89 \mathrm{a}$ & $1,49 b$ & $1,95 \mathrm{a}$ & $1,88 \mathrm{a}$ & 1,84 & 0,09 & $* *$ & $* *$ & ns \\
\hline Ácido valérico (Valeric acid) & 1,04 & 1,11 & 1,01 & 0,98 & 1,02 & 1,03 & 0,06 & ns & $* *$ & $\mathrm{~ns}$ \\
\hline $\mathrm{C} 2: \mathrm{C} 3$ & $3,34 b$ & $2,96 \mathrm{c}$ & $3,02 \mathrm{c}$ & $3,56 a$ & $3,15 \mathrm{ab}$ & 3,21 & 0,07 & $*$ & $* *$ & ns \\
\hline AGV totais (Total VFA) & $96,60 \mathrm{ab}$ & $100,80 \mathrm{a}$ & $90,3 \mathrm{ab}$ & $97,10 \mathrm{ab}$ & $86,80 \mathrm{~b}$ & 94,30 & 3,32 & $* *$ & $*$ & $\mathrm{~ns}$ \\
\hline $\mathrm{pH}$ & 6,80 & 6,75 & 6,74 & 6,77 & 6,84 & 6,78 & 0,04 & ns & $* *$ & $\mathrm{~ns}$ \\
\hline
\end{tabular}

${ }^{1}$ Efeito: 1 = silagem; 2 = horário de coleta; 3 = interação silagem $\times$ horário de coleta (Effect: 1 = treatments; 2 = sampling time; $3=$ interaction treatments $\times$ sampling time). Médias seguidas de letras diferentes na linha são diferentes pelo teste Tukey-Kramer $(\mathrm{P}<0,05)$; ns - Não-significativo (Means followed by different letters, within a row, are different by adjusted Tukey-Kramer test $(P<0.05)$; NS - not significant). 

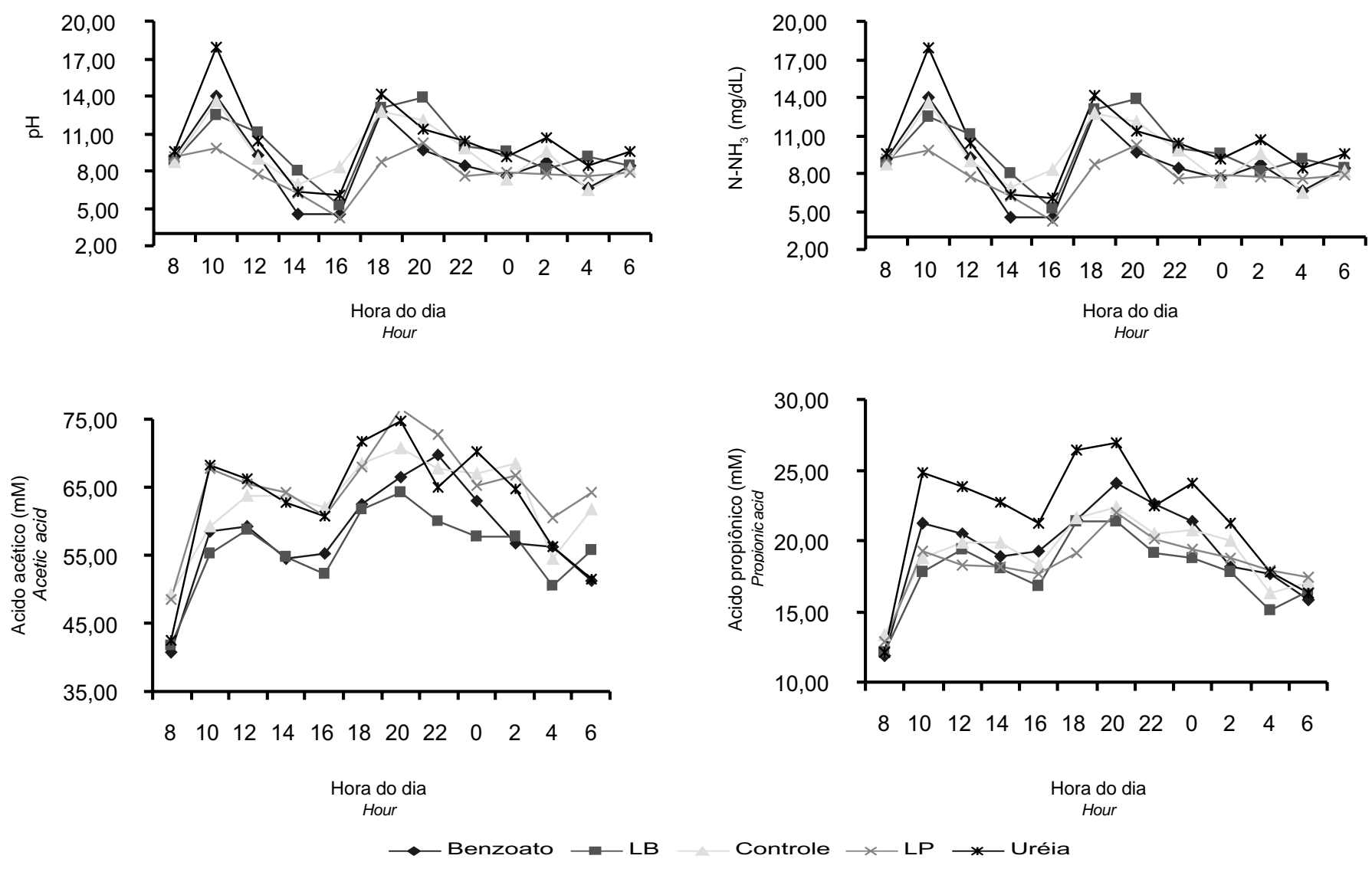

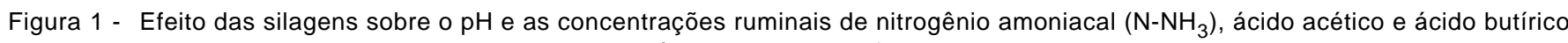
em bovinos. As horas do dia indicam os horários de coleta de fluido ruminal.

Figure 1 - Effect of silages on $\mathrm{pH}$ and ruminal concentration of ammoniacal nitrogen $\left(\mathrm{N}^{-} \mathrm{NH}_{3}\right)$, acetic and butyric acid in beef steers. The hours of the day indicate the schedules of ruminal fluid collection.

res de ácidos acético e propiônico de 65,2 e 12,5 mM e relação ácidos acético: propiônico de 5,2:1. Paziani (2004) observou relação ácidos acético: propiônico de 4,6:1 para dietas com silagem de capim-tanzânia, como resultado das menores concentrações de ácido propiônico $(12,4 \mathrm{mM})$. Aumentos na concentração molar de propionato no rúmen podem estar relacionados ao maior aporte de $\mathrm{CHO}$ fermentescíveis (Bergman, 1990), como a sacarose, em dietas com silagem de cana-de-açúcar.

As curvas de concentração ruminal dos ácidos acético e propiônico apresentaram tendência semelhante, com rápida elevação a partir da alimentação matinal e pico de maior magnitude próximo ao horário de alimentação vespertina. As concentrações molares de ambos os ácidos foram mais altas na silagem com uréia e mais baixas na silagem com Lactobacillus buchneri (Tabela 2).

A dieta com silagem produzida com uréia acarretou maior concentração ruminal dos ácidos propiônico e butírico (Tabela 2), o que pode estar relacionado ao maior teor de $\mathrm{PB}$ e $\mathrm{N}-\mathrm{NH}_{3}$ dessas silagens para crescimento microbiano ruminal.
Apesar de não terem sido afetados pelas silagens (Tabela 2), os valores médios de $\mathrm{pH}(6,78)$ tiveram efeito significativo do horário de amostragem (Tabela 3 ). Houve redução acentuada no $\mathrm{pH}$ ruminal logo após o fornecimento da alimentação matinal $(8 \mathrm{~h})$ e vespertina $(18 \mathrm{~h})$. Essa tendência indica alta produção de ácidos logo após as refeições (Figura 1), em decorrência do teor de carboidratos rapidamente fermentescíveis nas dietas contendo silagem de cana-de-açúcar.

$\mathrm{O}$ pH ruminal é uma variável correlacionada ao comportamento ingestivo do animal e que depende do tempo de mastigação e salivação e da freqüência de ingestão e ruminação, entre outros (Paziani, 2004). O valor do pH ruminal pode ser mantido pelo aumento no poder de neutralização pela saliva ou diminuído pela produção de ácidos (Church, 1993). A saliva é importante para remoção do íon $\mathrm{H}^{+}$da solução ruminal, pois contém carbonato, que, ligado ao $\mathrm{H}^{+}$, forma água e $\mathrm{CO}_{2}$ (Allen, 1997). Também apresenta elevado poder tamponante, em virtude da grande quantidade de sais de Na e K, que neutralizam ácidos produzidos na fermentação (Dixon \& Stockdale, 1999). 
Paziani (2004) avaliou parâmetros ruminais de bovinos alimentados com dietas contendo silagem de capim-tanzânia ( $86 \%$ da MS) e verificou $\mathrm{pH}$ ruminal semelhante, com redução dos valores após as refeições. Contudo, a velocidade de redução no $\mathrm{pH}$ foi menor, com os valores mínimos 8 horas após as refeições. Provavelmente essa redução mais lenta no $\mathrm{pH}$ ruminal foi ocasionada pelo menor teor de carboidratos solúveis $(0,9 \%$ da $\mathrm{MS})$ das silagens de gramíneas tropicais em comparação às de cana utilizadas neste estudo.

Dixon \& Stockdale (1999) afirmaram que o $\mathrm{pH}$ ruminal ótimo para digestão microbiana da fibra é de 6,6 a 7,0 e que o nível crítico para pH é abaixo de 6,0. Neste experimento, os valores de $\mathrm{pH}$ variaram entre 7,2 e 6,4, indicando teor adequado de FDN nas rações para manter estabilidade no ambiente ruminal e favorecer a digestão da MO.

A concentração ruminal de nitrogênio na forma amoniacal $\left(\mathrm{N}-\mathrm{NH}_{3}\right)$ foi influenciada pelas rações testadas, com maiores valores para as silagens com uréia e Lactobacillus buchneri e o menor valor para a silagem LP.

A análise da concentração ruminal de nitrogênio amoniacal evidenciou picos imediatamente após as refeições (Figura 1), provavelmente em virtude da alta solubilidade da uréia das rações. A silagem uréia destacou-se com picos mais elevados, embora estatisticamente iguais aos obtidos na silagem LB.

As concentrações de $\mathrm{N}-\mathrm{NH}_{3}$ foram suficientes para promover crescimento bacteriano adequado, conforme valor mínimo de $5 \mathrm{mg} \mathrm{N}-\mathrm{NH}_{3} / \mathrm{dL}$ determinado por Preston (1986), citado por Silveira et al. (2002). Neste estudo, os valores médios variaram entre 5,6 e 13,6 mg/dL, dependendo do horário de amostragem (Tabela 3 ).

A maioria das bactérias ruminais é capaz de utilizar $\mathrm{N}-\mathrm{NH}_{3}$ como fonte de nitrogênio para síntese de proteína microbiana, no entanto, a quantidade de $\mathrm{N}-\mathrm{NH}_{3}$ freqüentemente produzida pela fermentação ruminal de proteínas e uréia é superior ao que os microrganismos podem utilizar. Parte do excesso de amônia produzida após a alimentação é absorvida e reciclada no rúmem via saliva secretada durante a ruminação (Van Soest, 1994; Huntington \& Archibeque, 1999).

Nesta pesquisa, a reciclagem de $\mathrm{N}-\mathrm{NH}_{3}$ via saliva pode explicar a manutenção dos níveis ruminais desse componente no período noturno ( $22 \mathrm{~h}$ às $8 \mathrm{~h}$ ), em decorrência do maior tempo dedicado à ruminação nesse período.

A Tabela 3 foi elaborada com valores médios de todos as silagens, para cada horário de coleta de amostras, uma vez que não foi observada interação silagem $\times$ horários de coleta.

A relação acético:propiônico $(\mathrm{C} 2: \mathrm{C} 3)$ manteve-se relativamente constante entre os horários de coleta e variou entre 3,04 e 3,60. Os valores médios de $\mathrm{pH}$ ruminal condizem com as concentrações de ácidos observadas; o valor mais elevado $(7,2)$ foi verificado às $8 \mathrm{~h}$ e o menor $(6,4)$, às $20 \mathrm{~h}$.

A concentração ruminal de $\mathrm{N}_{-} \mathrm{NH}_{3}$ apresentou picos logo após o fornecimento das rações; os valores máximos observados foram 13,57 e 12,26 mg/dL para os períodos da manhã e tarde, respectivamente.

O cálculo da degradabilidade efetiva in situ das frações MS, MO, FDN e FDA das silagens (Tabelas 4 e 5) foi realizado mediante modelo proposto pelo Fit Curve (Hovell, 1995), considerando valores de taxa de passagem (kp) de 2, 5 e $8 \%$ /hora estabelecidos pelo programa. A análise da degradabilidade da MS (Tabela 4) comprovou diferença estatística $(\mathrm{P}<0,05)$ nas concentrações da fração " $a$ " das silagens, que variaram entre 31,0 e $24,9 \%$. Esse resultado não está de acordo com a avaliação do conteúdo de carboidratos solúveis de silagens realizada por Schmidt et al. (2007), que obtiveram valor consideravelmente superior para o tratamento benzoato em relação aos demais.

O teor de fração potencialmente degradável " $b$ ", a taxa de degradação " $c$ ” e o tempo de colonização não foram influenciados pelos aditivos utilizados nas silagens e apresentaram valores médios de $28,1 \%, 3,53 \%$ /hora e 7,39 horas, respectivamente.

Fernandes et al. (2003) avaliaram a composição fracional dos carboidratos da cana-de-açúcar em diferentes idades de corte pelo método de produção de gás in vitro e obtiveram valores médios de $48,8 \%$ para fração " $a$ ", 30,4\% para fração " $b$ " e $28,3 \%$ para a fração indigestível. Os dados obtidos por esses autores se assemelham aos deste estudo quanto ao teor de fração " $b$ ", no entanto, os teores de fração solúvel " $a$ " foram mais elevados, provavelmente em decorrência do consumo de carboidratos solúveis no processo de ensilagem.

A degradabilidade potencial da MS, determinada no modelo do Fit Curve como soma das frações " $a$ " e " $b$ " foi maior para a silagem com uréia $(58,3 \%)$ e menor para a silagem com $L$. plantarum $(54,9 \%)$, conforme resultado verificado para a fração " $a$ ". A degradabilidade efetiva da MS, estimada para valores de taxa de passagem $(k p)$ de 2 , 5 e $8 \%$ /hora, foi maior para as silagens contendo Uréia, LB e benzoato.

A avaliação da composição bromatológica das silagens realizada por Schmidt et al. (2007) evidenciou menores teores de FDN e FDA para a silagem adicionada de uréia e maiores teores para a silagem inoculada com L. plantarum, o que pode explicar parcialmente as diferenças quanto à degradabilidade efetiva desses volumosos. Contudo, a estimativa isolada da fração " $b$ " não corresponde a essa tendência, o que poderia sugerir que variações qualitativas da fração FDN entre as silagens poderiam também influenciar a degradabilidade efetiva da MS. 
Tabela 3 - Parâmetros ruminais em bovinos alimentados com rações contendo silagem de cana-de-açúcar Table 3 - Ruminal parameters of beef steers fed sugar cane silage based diets

\begin{tabular}{|c|c|c|c|c|c|c|c|c|c|c|}
\hline \multirow[t]{2}{*}{$\begin{array}{l}\text { Hora }^{1} \\
\text { Hour }\end{array}$} & \multicolumn{7}{|c|}{$\begin{array}{c}\text { Ácidos graxos voláteis, } \mathrm{mM} \mathrm{pH} \\
\text { Volatile fatty acids, } \mathrm{mM}\end{array}$} & \multirow[t]{2}{*}{$\mathrm{pH}$} & \multirow[t]{2}{*}{ Total $^{2}$} & \multirow[t]{2}{*}{$\mathrm{N}-\mathrm{NH}_{3}-(\mathrm{mg} / \mathrm{dL})$} \\
\hline & $\mathrm{C} 2$ & $\mathrm{C} 3$ & $\mathrm{C} 4$ & IC4 & C5 & IC 5 & $\mathrm{C} 2: \mathrm{C} 3$ & & & \\
\hline $8: 00$ & 44,60 & 12,40 & 5,58 & 1,22 & 0,57 & 1,78 & 3,60 & 68,70 & 7,19 & 9,10 \\
\hline $10: 00$ & 61,80 & 20,40 & 10,50 & 1,07 & 1,16 & 2,12 & 3,05 & 100,80 & 6,88 & 13,60 \\
\hline $12: 00$ & 62,70 & 20,40 & 11,10 & 0,97 & 1,16 & 1,97 & 3,11 & 102,10 & 6,70 & 9,50 \\
\hline $14: 00$ & 60,10 & 19,50 & 10,50 & 0,85 & 1,09 & 1,75 & 3,10 & 97,50 & 6,68 & 6,40 \\
\hline $16: 00$ & 58,20 & 18,60 & 10,20 & 0,92 & 0,98 & 1,73 & 3,14 & 94,30 & 6,79 & 5,65 \\
\hline $18: 00$ & 66,50 & 22,00 & 11,70 & 0,93 & 1,10 & 1,79 & 3,07 & 108,20 & 6,72 & 12,30 \\
\hline $20: 00$ & 70,60 & 23,30 & 13,00 & 0,89 & 1,29 & 1,87 & 3,04 & 115,30 & 6,42 & 11,40 \\
\hline $22: 00$ & 67,00 & 21,00 & 11,70 & 0,93 & 1,14 & 1,80 & 3,22 & 107,60 & 6,51 & 9,22 \\
\hline $0: 00$ & 64,70 & 20,80 & 11,20 & 0,96 & 1,14 & 1,81 & 3,12 & 104,60 & 6,63 & 8,31 \\
\hline $2: 00$ & 62,90 & 19,20 & 10,30 & 1,05 & 1,03 & 1,85 & 3,28 & 100,10 & 6,85 & 8,93 \\
\hline 4:00 & 55,60 & 17,00 & 8,75 & 1,07 & 0,87 & 1,77 & 3,30 & 88,40 & 6,91 & 7,63 \\
\hline $6: 00$ & 56,90 & 16,60 & 8,43 & 1,11 & 0,85 & 1,81 & 3,47 & 89,10 & 7,07 & 8,46 \\
\hline
\end{tabular}

${ }_{1}^{1}$ Horário em que foram realizadas as amostragens (Day-time of sampling).

2 Soma das concentrações dos ácidos acético, propiônico, butírico, isobutírico, valérico e isovalérico (Sum of acetic, propionic, butyric, isobutyric, valeric and isovaleric acids).

A taxa de degradação "c", o tempo de colonização e a degradabilidade potencial não diferiram entre as silagens e apresentaram valores médios de 3,41\%/hora, 7,71 horas e $56,2 \%$, respectivamente. A degradabilidade efetiva da MO apresentou tendência semelhante à observada para MS, provavelmente em razão da similaridade no teor de minerais (cinzas) entre as silagens, com valores médios de 46,7; 41,3 e $39,0 \%$, para valores de $k p$ de 2,5 e $8 \%$ /hora, respectivamente.

A degradabilidade in situ dos carboidratos estruturais (FDN e FDA) não diferiru entre as silagens (Tabela 5). Os teores médios estimados para as frações " $a$ " e " $b$ " foram, respectivamente, de 8,45 e $34,5 \%$ para a FDN e 6,75 e $36,3 \%$ para a FDA.

Em quatro das 25 observações, foram obtidos valores negativos para a fração " $a$ " das silagens, o que pode estar relacionado a desvios na predição dessa fração pelo programa, em decorrência do elevado coeficiente de variação (42,5\% para FDN e 59,5\% para FDA), conforme relatado por Loures et al. (2005) e Paziani (2004). Nesse caso, o procedimento adotado foi substituir o valor negativo por zero, uma vez que não existe fração " $a$ " negativa.

Teoricamente, a proporção da fração " $a$ " na FDN e FDA deveria ser próxima a zero por ser uma fração prontamente solúvel no rúmen no tempo zero de incubação. Contudo, o programa estimou teores médios de fração " $a$ " de 8,45 e 6,75\% para a FDN e FDA, possivelmente em virtude da perda de partículas diminutas durante a lavagem dos sacos não incubados. O mesmo foi observado por outros autores em silagens de gramíneas tropicais (Balsalobre, 2002; Paziani, 2004).

O teor médio de fração " $b$ " foi de $34,5 \%$ para a FDN e $36,3 \%$ para a FDA, com taxas de degradação médias “ $c$ " de 3,17 e $3,15 \%$ /hora e tempos de colonização médios de 7,96 e 7,49 horas.
Avaliando a degradabilidade da FDN de silagens de capim-tanzânia, Paziani (2004) verificou valores médios de "b" e "c" e tempo de colonização de 58,8\%; 4,5\%/hora e 3,0 horas, respectivamente. Do mesmo modo, os valores de degradabilidade da FDA foram próximos aos obtidos para a FDN. Nota-se, portanto, que a cana-de-açúcar possui menor teor de fração " $b$ ", porém, com taxa de digestão mais lenta para essa fração, além de maior tempo de colonização, em comparação ao capim-tanzânia.

Pires et al. (2004) avaliaram a degradabilidade ruminal do bagaço de cana-de-açúcar e verificaram teores de fração “ $b$ " de 44,0\% para a FDN e 42,6\% para a FDA. Os valores de degradação potencial e efetiva da FDN e FDA observados neste estudo foram inferiores aos valores estimados para as frações MS e MO. A degradabilidade potencial da FDN e da FDA apresentaram valores médios de 42,9 e 43,0\%. A degradabilidade efetiva da FDN estimada foi de 30,1; 23,3 e $20,3 \%$ para as taxas de passagem de 2,5 e $8 \%$ /hora, respectivamente. Para a FDA, os valores obtidos foram de 29,4; 22,2 e $19,2 \%$ para os três valores de taxa de passagem mencionados.

Franzolin \& Franzolin (2000) avaliaram a cinética de degradação da cana-de-açúcar em bovinos e bubalinos e verificaram valores médios de degradabilidade potencial da MS e da FDN de 79,3 e 74,5\%, com degradabilidade efetiva da MS e da FDN ( $k p$ de 5\%/hora) de 56,5 e 31,6\%, respectivamente. Os valores obtidos por esses autores para canade-açúcar fresca são bastante superiores aos verificados neste experimento, contudo, esses autores não informaram a composição químico-bromatológica do volumoso, o que limita a comparação dos resultados.

As estimativas do tempo de colonização (lag time) para MS, MO, FDN e FDA apresentaram alto coeficiente de 
variação, o que impediu a determinação de diferenças entre silagens. Esse mesmo efeito foi verificado por Paziani (2004) para a degradabilidade ruminal de capim-tanzânia, com base no modelo do Fit Curve.

\section{Conclusões}

O uso de aditivos na ensilagem de cana-de-açúcar promoveu pequenas alterações na degradabilidade ruminal

Tabela 4 - Degradabilidade in situ da MS e MO de silagens de cana-de-açúcar em bovinos Table 4 - In situ DM and OM degradability of sugar cane silages in beef steers

\begin{tabular}{|c|c|c|c|c|c|c|c|}
\hline \multirow[t]{2}{*}{ Item } & \multicolumn{5}{|c|}{$\begin{array}{l}\text { Silagem } \\
\text { Silage }\end{array}$} & \multirow[t]{2}{*}{$\begin{array}{l}\text { Média } \\
\text { Mean }\end{array}$} & \multirow[t]{2}{*}{$\mathrm{CV}, \%$} \\
\hline & $\begin{array}{l}\text { Controle } \\
\text { Control }\end{array}$ & $\begin{array}{l}\text { Uréia } \\
\text { Urea }\end{array}$ & $\begin{array}{c}\text { Benzoato } \\
\text { Benzoate }\end{array}$ & LP & LB & & \\
\hline \multicolumn{8}{|l|}{ MS (DM) } \\
\hline Fração $a, \%$ (Fraction $a$ ) & $29,20 \mathrm{ab}$ & $31,0 \mathrm{a}$ & $29,40 \mathrm{ab}$ & $24,90 b$ & $29,0 \mathrm{ab}$ & 28,70 & 8,41 \\
\hline Fração $b, \%$ (Fraction $b$ ) & 27,50 & 27,30 & 28,20 & 30,00 & 27,30 & 28,10 & 5,46 \\
\hline$c, \% /$ hora & 3,27 & 3,70 & 3,64 & 3,54 & 3,49 & 3,53 & 13,10 \\
\hline Tempo de colonização, hora (Lag time, hour) & 7,36 & 7,08 & 5,93 & 5,88 & 10,70 & 7,39 & 83,30 \\
\hline Deg. potencial, \% (Potencial degradability) & $56,80 \mathrm{ab}$ & $58,30 \mathrm{a}$ & $57,60 \mathrm{ab}$ & $54,90 \mathrm{~b}$ & $56,30 \mathrm{ab}$ & 56,80 & 3,09 \\
\hline Deg. efetiva, $\% ; \mathrm{kp}=2 \%$ /hora (Effective degradability) & $46,80 \mathrm{ab}$ & $49,20 \mathrm{a}$ & $48,00 \mathrm{a}$ & $44,20 b$ & $44,30 \mathrm{ab}$ & 46,50 & 3,87 \\
\hline Deg. efetiva, $\% ; \mathrm{kp}=5 \% /$ hora (Effective degradability) & $41,20 \mathrm{ab}$ & $43,80 \mathrm{a}$ & $42,30 \mathrm{a}$ & $38,10 \mathrm{~b}$ & $42,30 \mathrm{a}$ & 41,50 & 5,10 \\
\hline Deg. efetiva, $\% ; \mathrm{kp}=8 \%$ /hora (Effective degradability) & $38,80 \mathrm{ab}$ & $41,30 \mathrm{a}$ & $39,70 \mathrm{ab}$ & $35,30 \mathrm{~b}$ & $40,20 \mathrm{a}$ & 39,10 & 6,09 \\
\hline \multicolumn{8}{|l|}{$\mathrm{MO}(\mathrm{OM})$} \\
\hline Fração $b, \%$ (Fraction $b$ ) & $26,50 \mathrm{ab}$ & $26,60 \mathrm{ab}$ & $27,80 \mathrm{ab}$ & $29,20 a$ & $25,80 \mathrm{~b}$ & 27,20 & 6,37 \\
\hline$c, \% /$ hora & 3,20 & 3,60 & 3,66 & 3,35 & 3,24 & 3,41 & 15,70 \\
\hline Tempo de colonização, hora (Lag time, hour) & 8,16 & 7,28 & 6,18 & 5,93 & 11,00 & 7,71 & 94,70 \\
\hline Deg. potencial, \% (Potencial degradability) & 56,20 & 57,80 & 57,00 & 54,30 & 55,90 & 56,20 & 3,30 \\
\hline Deg. efetiva, $\% ; \mathrm{kp}=2 \% /$ hora (Effective degradability) & $46,40 \mathrm{ab}$ & $48,80 \mathrm{a}$ & $47,50 \mathrm{a}$ & $43,70 b$ & $47,10 \mathrm{ab}$ & 46,70 & 4,08 \\
\hline Deg. efetiva, $\% ; \mathrm{kp}=5 \% /$ hora (Effective degradability) & $41,20 \mathrm{ab}$ & $43,50 \mathrm{a}$ & $41,90 \mathrm{a}$ & $37,70 b$ & $42,40 \mathrm{a}$ & 41,30 & 5,35 \\
\hline Deg. efetiva, $\% ; \mathrm{kp}=8 \%$ /hora (Effective degradability) & $39,00 \mathrm{ab}$ & $41,20 \mathrm{a}$ & $39,40 \mathrm{ab}$ & $35,00 \mathrm{~b}$ & $40,40 \mathrm{a}$ & 39,00 & 6,31 \\
\hline
\end{tabular}

Médias seguidas de letras diferentes, na linha, são diferentes $(P<0,05)$ pelo teste Tukey.

Means followed by different letters, within a row, differ $(P<0.05)$ by Tukey test.

Tabela 5 - Degradabilidade in situ da FDN e FDA de silagens de cana-de-açúcar em bovinos

Tabela 5 - In situ NDF and ADF degradability of sugar cane silages in beef steers

\begin{tabular}{|c|c|c|c|c|c|c|c|}
\hline \multirow[t]{2}{*}{ Item } & \multicolumn{5}{|c|}{$\begin{array}{l}\text { Silagem } \\
\text { Silage }\end{array}$} & \multirow[t]{2}{*}{$\begin{array}{l}\text { Média } \\
\text { Mean }\end{array}$} & \multirow[t]{2}{*}{$\mathrm{CV}, \%$} \\
\hline & $\begin{array}{c}\text { Controle } \\
\text { Control }\end{array}$ & $\begin{array}{l}\text { Uréia } \\
\text { Urea }\end{array}$ & $\begin{array}{c}\text { Benzoato } \\
\text { Benzoate }\end{array}$ & LP & LB & & \\
\hline \multicolumn{8}{|l|}{ FDN (NDF) } \\
\hline Fração $a, \%$ (Fraction $a$ ) & 10,90 & 7,23 & 6,46 & 7,34 & 10,30 & 8,45 & 42,50 \\
\hline Fração $b, \%$ (Fraction $b$ ) & 33,80 & 35,40 & 35,90 & 35,20 & 32,40 & 34,50 & 8,54 \\
\hline$c, \% /$ hora & 2,79 & 3,20 & 3,28 & 3,23 & 3,37 & 3,17 & 15,00 \\
\hline Tempo de colonização, hora (Lag time, hour) & 8,12 & 6,43 & 6,01 & 6,94 & 12,30 & 7,96 & 97,50 \\
\hline Deg. potencial, \% (Potencial degradability) & 44,70 & 42,20 & 42,30 & 42,40 & 42,70 & 42,90 & 5,83 \\
\hline Deg. efetiva, $\% ; \mathrm{kp}=2 \% /$ hora (Effective degradability) & 31,00 & 29,10 & 29,20 & 29,30 & 31,90 & 30,10 & 9,81 \\
\hline Deg. efetiva, $\% ; \mathrm{kp}=5 \% /$ hora (Effective degradability) & 24,30 & 22,00 & 21,80 & 22,10 & 26,10 & 23,30 & 15,20 \\
\hline Deg. efetiva, $\% ; \mathrm{kp}=8 \% /$ hora (Effective degradability) & 21,50 & 19,00 & 18,60 & 19,00 & 23,30 & 20,30 & 19,20 \\
\hline \multicolumn{8}{|l|}{ FDA $(A D F)$} \\
\hline Fração $b, \%$ (Fraction $b$ ) & 34,90 & 37,30 & 38,70 & 36,50 & 34,00 & 36,30 & 9,00 \\
\hline$c, \% /$ hora & 2,71 & 3,21 & 3,21 & 3,30 & 3,31 & 3,15 & 13,20 \\
\hline Tempo de colonização, hora (Lag time, hour) & 7,74 & 6,68 & 5,92 & 6,10 & 11,00 & 7,49 & 96,70 \\
\hline Deg. potencial, \% (Potencial degradability) & 45,50 & 42,40 & 41,90 & 43,20 & 42,00 & 43,00 & 5,78 \\
\hline Deg. efetiva, $\% ; \mathrm{kp}=2 \% /$ hora (Effective degradability) & 31,00 & 28,60 & 27,40 & 29,80 & 30,40 & 29,40 & 9,53 \\
\hline Deg. efetiva, $\% ; \mathrm{kp}=5 \% /$ hora (Effective degradability) & 24,00 & 21,10 & 19,40 & 22,30 & 24,30 & 22,20 & 14,60 \\
\hline Deg. efetiva, $\% ; \mathrm{kp}=8 \% /$ hora (Effective degradability) & 21,20 & 18,00 & 15,90 & 19,00 & 21,80 & 19,20 & 18,50 \\
\hline
\end{tabular}

Médias seguidas de letras diferentes, na linha, são diferentes $(P<0,05)$ pelo teste Tukey.

Means followed by different letters, within a row, differ $(P<0.05)$ by Tukey test. 
da MS das silagens e não afetou a degradabilidade dos componentes da parede celular. Os valores obtidos para a cana-de-açúcar ensilada foram próximos aos relatados para a planta fresca.

O perfil fermentativo e o ambiente ruminal proporcionado por rações contendo silagens de cana-de-açúcar foram satisfatórios e similares ao tradicionalmente observado em rações contendo cana.

\section{Literatura Citada}

ALLEN, M.S. Relationship between fermentation acid production in the rumen and the requirement for physically effective fiber. Journal of Dairy Science, v. 80, n.7, p.1447-1462, 1997.

ASSOCIATION OF OFFICIAL ANALYTICAL CHEMISTS - AOAC. Official methods of analysis. 15.ed. Arlington: 1990. v.1, $1117 \mathrm{p}$.

BALSALOBRE, M.A.A Valor alimentar do capim Tanzânia irrigado. Piracicaba: Escola Superior de Agricultura "Luiz de Queiroz", 2002. 113p. Tese (Doutorado em Agronomia) - Escola Superior de Agricultura "Luiz de Queiroz", 2002.

BERGMAN, E.N. Energy contributions of volatile fatty acids from the gastrointestinal tract in various species. Physiological Reviews, v.70, n.2, p.567-590, 1990.

CHANEY, A.L.; MARBACH, E.P. Modified reagents for determination of urea and ammonia. Clinical Chemistry, v. 8, p. $130-137,1962$.

CHURCH, D.C. The ruminant animal digestive physiology and nutrition. 2.ed. New Jersey: Waveland, 1993. 564p.

DIXON, R.M.; STOCKDALE, C.R. Associative effects between forages and grains: consequences for feed utilisation. Australian Journal of Agricultural Research, v.50, p.757-773, 1999.

FERNANDES, A.M.; QUEIROZ, A.C.; LANA, R.P. et al. Estimativas da produção de leite por vacas holandesas mestiças, segundo o sistema CNCPS, em dietas contendo cana-de-açúcar com diferentes valores nutritivos. Revista Brasileira de Zootecnia, v.30, n.4, p.1350-1357, 2001

FERNANDES, A.M.; QUEIROZ, A.C.; PEREIRA, J.C. et al. Fracionamento e cinética da degradação in vitro dos carboidratos constituintes da cana-de-açúcar com diferentes ciclos de produção em três idades de corte. Revista Brasileira de Zootecnia, v.32, n.6, p.1778-1785, 2003. (supl.1)

FRANZOLIN, R.; FRANZOLIN, M.H.T. População protozoários ciliados e degradabilidade ruminal em búfalos e bovinos zebuínos sob dieta à base de cana-de-açúcar. Revista Brasileira de Zootecnia, v.29, n.6, p.1853-1861, 2000.

HOLDEN, L.A. Comparison of methods of in vitro dry matter digestibility for ten feeds. Journal of Dairy Science, v.82, n. 8, p.1791-1794, 1999.

HOVELL, F.D.B. [1995]. Measurement of roughage or protein degradation using the polyester bag "in sacco" technique. Fit curve user manual. Disponível em: <http:// www.macaulay.ac.uk/IFRU/software>. Acesso em: 22/1/2006.

HUntington, G.B.; ARCHIBeQue, S.L. [1999]. Practical aspects of urea and ammonia metabolism in ruminants. Disponível em: <http://www.asas.org/symposia/proceedings/ 0939.pdf>. Acesso em: 10/6/2005.

HUNTINGTON, J.A.; GIVENS, D.I. The in situ technique for studying the rumen degradation of feeds: a review of the procedure. Nutricional Abstracts and Reviews (Series B), v. 65, n. 2, p.63-93, 1995.

LIMA, J.A.; EVANGELISTA, A.R.; ABREU, J.G. et al. Silagem de cana-de-açúcar (Saccharum officinarum L.) enriquecida com uréia ou farelo de soja. In: REUNIÃO ANUAL DA SOCIEDADE BRASILEIRA DE ZOOTECNIA, 39., 2002, Recife. Anais... Recife: Sociedade Brasileira de Zootecnia, 2002. (CD-ROM).

LOURES, D.R.S.; NUSSIO, L.G.; PAZIANI, S.F. et al. Efeito de enzimas fibrolíticas e do teor de matéria seca em silagens de capim-Tanzânia sobre os parâmetros ruminais, o comportamento ingestivo e a digestão de nutrientes em bovinos. Revista Brasileira de Zootecnia, v.34, n.3, p.736-745, 2005.

McDONALD, P.; HENDERSON, A.R.; HERON, S.J.E. The biochemistry of silage. 2.ed. Marlow: Chalcombe Publications, 1991. 340p.

NATIONAL RESEARCH COUNCIL - NRC. Nutrients requirements of beef cattle. 7.ed. Washington: National Academy of Sciences, 1996. 242p.

NOCEK, J.E. In situ and other methods to estimate ruminal protein and energy digestibility: a review. Journal of Dairy Science, v.71, n.10, p.2051-2069, 1988 .

ØRSKOV, E.R.; McDONALD, I. The estimation of protein degradability in the rumen from incubation measurements weighted according to rate of passage. Journal of Agricultural Science, v.92, p.499-503, 1979.

PAZIANI, S.F. Controle de perdas na ensilagem, desempenho e digestão de nutrientes em bovinos de corte alimentados com rações contendo silagens de capim tanzânia. Piracicaba: Escola Superior de Agricultura "Luiz de Queiroz", 2004. 208p. Tese (Doutorado em Agronomia) - Escola Superior de Agricultura "Luiz de Queiroz", 2004.

PIRES, A.J.V.; GARCIA, R.; VALADARES FILHO, S.C. et al. Degradabilidade do bagaço de cana-de-açúcar tratado com amônia anidra e, ou, sulfeto de sódio. Revista Brasileira de Zootecnia, v.33, n.4, p.1071-1077, 2004.

STATISTICAL ANALYSIS SYSTEM - SAS. SAS user's guide: statistics. Cary, 1996. 983p.

SCHMIDT, P.; MARI, L.J.; NUSSIO, L.G. et al. Aditivos químicos e biológios na ensilagem da cana-de-açucar. 1. Composição química das silagens, ingestão, disgestibilidade e comportamento ingestivo. Revista Brasileira de Zootecnia, v.36, n.5, p.16661675, 2007 (supl.).

SILVEIRA, R.N.; BERCHIELLI, T.T.; FREITAS, D. et al. Fermentação ruminal em bovinos alimentados com silagens de resíduos de mandioca e de cana-de-açúcar, com polpa cítrica peletizada. In: REUNIÃO ANUAL DA SOCIEDADE BRASILEIRA DE ZOOTECNIA, 39., 2002, Recife. Anais... Recife: Sociedade Brasileira de Zootecnia, 2002. (CD-ROM).

SIQUEIRA, G.R. Cana-de-açúcar (Saccharum officinarum L.) ensilada com aditivos químicos e microbianos. Jaboticabal: Universidade Estadual Paulista, 2005. 92p. Dissertação (Mestrado em Zootecnia) - Universidade Estadual Paulista, 2005.

Van SOEST, P.J. Nutritional ecology of the ruminant. 2.ed. New York: Cornell University Press, 1994. 476p. 